\title{
Histopatologia e imuno-histoquímica de camundongos C57BL/6 infectados por Toxoplasma gondii cepa ME-49 e alimentados com micotoxinas
}

\section{Histopatology and immunohistochemistry of C57BL/6 mice infected with Toxoplasma gondii ME-49 strain and fed with mycotoxins}

\author{
Danuza Pinheiro Bastos Garcia Mattos, ${ }^{*}$ Rosana Alves Martorelli, ${ }^{* *}$ Rodrigo Caldas Menezes, ${ }^{* *}$ Ronald Bastos Freire, ${ }^{* * *}$ \\ Janice Mery Chicarino de Oliveira Coelho, ${ }^{* * * *}$ Maria Regina Reis Amendoeira*****
}

\begin{abstract}
Resumo
A avaliação do curso da infecção por Toxoplasma gondii em camundongos alimentados com micotoxinas, utilizando a histopatologia e imuno-histoquímica, demonstrou a ocorrência de lesões mais acentuadas nos animais infectados e expostos às toxinas. Diferentes quadros de inflamação e necrose encefálica e hepática mostraram que a associação entre parasitismo e a ingestão das micotoxinas causou agravamento nas lesões. A fumonisina B1(FB1, isolada ou associada a outras micotoxinas) foi responsável por alterações celulares como gigantismo nuclear, hipertrofia celular e células atípicas em tecido hepático. A FB1 foi também relacionada com quadros de desmielinização em tecido cerebral. A presença de cistos ou formas livres da cepa ME-49 de T. gondii foi constatada tanto em animais controle quanto nos alimentados com micotoxinas, mostrando que a cepa do parasita, nesta linhagem C57BL/6 de camundongos, apresenta formas características de fase aguda e crônica da infecção.
\end{abstract}

Palavras-chave: Toxoplasma gondii, micotoxinas, histopatologia, imuno-histoquímica.

\begin{abstract}
The course of toxoplasmosis in mice fed with mycotoxins was evaluated by histopatology and immunohistochemistry. The most severe lesions was seen in animals infected by T. gondii and fed on mycotoxins, when they were compered with control animals. Encephalitis, hepatitis, necrosis foci in the brain and liver showed that the association parasite infection and micotoxicosis aggravated the lesions. The fumonisin B1(isolated or in adiccion to others mycotoxins) was responsable for cellular alteration like nuclear enlargement, cellular hypertrophy, and atypical cells in hepatic tissue. This mycotoxin was also related to brain desmyelinization. The presence of cysts or free parasites was observed in control and intoxicated animals. This result showed that ME49 strain of T. gondii, in C57BL/6 mice, can display typical forms of acute and chronic infection.
\end{abstract}

Keywords: Toxoplasma gondii, mycotoxins, histopatology, immunohistochemistry.

\section{Introdução}

A toxoplasmose é uma zoonose que acomete uma ampla variedade de espécies animais, inclusive o homem. Seu agente etiológico, Toxoplasma gondii (Nicolle e Manceaux, 1909) possui ampla dispersão pelo mundo (Amendoeira et al., 1999).

Em animais domésticos, as patologias associadas à toxoplasmose podem levar a abortos, morte neonatal e quedas na produção. Em humanos o quadro mais importante envolve a infecção congênita, podendo gerar abortos e uma série de alterações neurológicas, visuais e auditivas (Tenter et al., 2000; Remington et al., 2001).

A toxoplasmose é uma das principais causas de morte em indivíduos imunocomprometidos. O curso da infecção por $T$. gondii, geralmente assintomático em imunocompetentes, ocorre de forma diferente em imunocomprometidos, podendo acarretar quadros de severa encefalite ou generalizados (Ferreira e Borges, 2002).

* Professora assistente - Departamento de Microbiologia e Parasitologia - Instituto Biomédico - Universidade Federal Fluminense. E-mail: danuzamattos@vm.uff.br.

** Médica-veterinária autônoma.

*** Médico-veterinário do Serviço de Zoonoses - Instituto de Pesquisa Clínica Evandro Chagas - Fundação Oswaldo Cruz. E-mail: rodrigo.menezes@ipec.fiocruz.br.

**** Professor adjunto do Departamento de Biologia Animal, Instituto de Biologia, Universidade Federal Rural do Rio de Janeiro, Seropédica, RJ, Brasil. E-mail: rbfreire@ufrrj.br.

***** Médica chefe do Laboratório de Anatomia Patológica - Instituto de Pesquisa Clínica Evandro Chagas - Fundação Oswaldo Cruz. E-mail: sap@ipec.fiocruz.br.

****** Pesquisadora titular chefe do Laboratório de Toxoplasmose - Instituto Oswaldo Cruz - Fundação Oswaldo Cruz. E-mail: amendoei@ioc.fiocruz.br. 
A infecção pode ocorrer de duas formas: congênita (quando a gestante desenvolve uma infecção aguda, passando-a para o concepto) ou adquirida (pós-natal). As principais fontes de infecção adquirida envolvem água e alimentos contaminados com oocistos esporulados ou cistos teciduais (Dubey e Beattie, 1988; Amendoeira, 1995; Dubey, 2004).

O sistema imunológico é importante no controle da evolução da infecção por T. gondii no organismo hospedeiro. Üm imunocomprometimento pode ocorrer por diversas causas como algumas enfermidades (infecciosas ou não), tratamentos contra doenças autoimunes ou pós-transplante, ou ainda a exposição a substâncias potencialmente imunomoduladoras, como as micotoxinas (Ferreira e Borges, 2002).

As micotoxinas são metabólitos secundários de fungos, sendo tóxicos para humanos e outros animais em graus variáveis. Segundo Fink-Gremmels (1999), cerca de 23\% da produção mundial de alimentos estaria contaminada por micotoxinas. Dentre as mais importantes estão as aflatoxinas, fumonisinas, ocratoxinas, tricotecenos, zearalenona e alcalóides do ergot. Estas são responsáveis pela perda de milhões de dólares em todo o mundo com gastos em saúde humana e animal, e condenação de produtos agrícolas (Vasanthi e Bhat, 1998).

A severidade da micotoxicose depende de fatores como o tipo de micotoxina, duração da exposição e a dose, assim como a espécie do consumidor, sua idade e o estado nutricional (Peraica et al.,1999; Hussein e Brasel, 2001). A exposição crônica a pequenas doses de micotoxinas pode gerar efeitos imunomoduladores, carcinogênicos e teratogênicos, dependendo da micotoxina avaliada (Pitt, 2000).

O efeito imunomodulador de certas micotoxinas pode ser responsável por mudanças no curso da infecção, levando a quadros mais severos (Martorelli, 2003).

No presente trabalho, investigamos os possíveis efeitos patológicos ocorridos durante a infecção pelo $T$. gondii quando animais foram alimentados com micotoxinas, objetivando avaliar a influência de baixas doses de micotoxinas na relação parasito-hospedeiro.

\section{Material e métodos}

\section{Animais}

Um total de 120 camundongos fêmeas da linhagem C57BL/ 6 , pesando cerca de 12-18 g, oriundos do biotério central da FIOCRUZ (CECAL/FIOCRUZ) foram utilizados em todo o experimento in vivo, mantidos em gaiolas, aos pares, a $23^{\circ} \mathrm{C}$ e $50 \%$ de umidade relativa do ar, de acordo com as normas éticas da instituição. Os animais receberam como alimento ração acrescida de micotoxinas ou ração comercial sem níveis detectáveis de micotoxinas, e água ad libitum.

A experimentação animal foi realizada com a aprovação da Comissão de Ẽtica no Uso de Animais (CEUA- FIOCRUZ) concedida pelo parecer P0039-02.

\section{Origem da cepa do Toxoplasma gondii}

A cepa ME-49, na forma de cistos, foi mantida em camundongos por sucessivas passagens de 50 a 100 cistos cerebrais inoculados por via intraperitoneal.

\section{Micotoxinas}

As micotoxinas aflatoxina B1(AFB1), citrinina (CTR), fumonisina $B 1$ (FB1) e ocratoxina $A(O A)$ foram obtidas comercialmente do distribuidor Sigma Chemicals Co. (St. Louis, EUA). A CTR, FB1 e OA foram diluídas em PBS até a obtenção das doses desejadas que correspondem respectivamente a 0,23; 1,00 e $0,93 \mathrm{mg} / \mathrm{kg}$ de ração. A AFB1 foi diluída em azeite de oliva para obtenção da concentração final de $0,93 \mathrm{mg} / \mathrm{kg}$ de ração. Foram utilizadas as associações: AFB1 com FB1, CTR com $\mathrm{OA}$, e por fim todas as quatro micotoxinas associadas.

\section{Ração}

A ração comercial (para camundongos e ratos, NUVILAB CR1, Brasil) serviu como base e apresentou especificações nutricionais padrões para a espécie animal estudada. A ração foi pulverizada, acrescida de micotoxinas nas referidas dosagens e reconstituída em formas plásticas padronizadas com $4 \mathrm{~cm}^{3}$.

\section{Delineamento experimental}

Os animais receberam ração experimental contendo AFB1, FB1, CTR e OA, em doses subintoxicantes $(0,01 \%$ da respectiva DL50), fornecida a partir do 30 dia após infecção e por mais 30 dias.

Foram constituídos 10 grupos de 12 animais designados como: Controle (C) e Infectados (I); subdivididos de acordo com alimentação recebida contendo ou não micotoxinas da seguinte forma: C-C e I-C (alimentados com ração controle sem micotoxinas); C-F e I-F (alimentados com ração experimental contendo FB1); C-FA e I-FA (alimentados com ração experimental contendo FB1+AFB1), C-CO e I-CO (alimentados com ração experimental contendo CTR+AO); C-MIX e I-MIX (alimentados com ração experimental contendo $\mathrm{FB} 1+\mathrm{AFB1}+\mathrm{CTR}+\mathrm{OA})$.

Três animais de cada grupo foram eutanasiados em intervalos de cinco dias, a partir do 15 dia pós-infecção. Foram coletadas amostras de cérebro, coração, pulmão, músculo esquelético, fígado e rins, que após fixação em formalina tamponada a 10\%, foram desidratadas e embebidas em parafina, sendo posteriormente processadas e avaliadas pela histopatologia e imuno-histoquímica.

\section{Histopatologia}

Três amostras longitudinais $\left(4 \mu \mathrm{m}\right.$ por $\left.30 \mathrm{~mm}^{2}\right)$ de cada tecido foram corados com hematoxilina-eosina (HE). Diversas regiões dos tecidos foram examinadas.

\section{Imuno-histoquímica}

O estudo imuno-histoquímico foi realizado de acordo com metodologia clássica, adaptada às condições do Laboratório. Brevemente, utilizou-se como anticorpo primário um policlonal anti-T. gondii, produzido no Laboratório de Biologia Estrutural do Instituto Oswaldo Cruz. Como anticorpo secundário biotinilado foi usado um policlonal anti-lg de camundongos, caprinos e coelhos (DAKO, LSAB + SYSTEM,HRP, EUA) seguido pelo complexo estreptavidina conjugada à peroxidase (DAKO, LSAB + SYSTEM,HRP, EUA) 
e como revelador a diaminobenzidina (DAB, da marca DAKO, EUA). A hematoxilina de Meyer foi utilizada para contracorar.

\section{Resultados e discussão}

A análise histopatológica dos cortes de cérebro dos animais não infectados dos grupos C-F, C-FA, C-MIX demonstrou alterações leves com pequenas áreas apresentando infiltrado mononuclear focal e discreta desmielinização (Figura 1, A). O mesmo não foi observado nos grupos C-C e C-CO. Nos animais infectados com T. gondii observaram-se cistos de tamanhos variados e ampla dispersão por todo o tecido encefálico, independentemente do tipo de alimentação que receberam. As alterações patológicas observadas variaram desde pequenas áreas de infiltrado mononuclear no parênquima, manguitos perivasculares, gliose (encontradas em animais dos grupos I-C, I-CO e I-MIX), até alterações mais severas como observado nos grupos I-F e IFA apresentando meningo-encefalites com focos de necrose e acentuada desmielinização. Nos grupos I-F e I-FA, alguns animais tiveram cistos com intensa reação mononuclear $\mathrm{e}$ polimorfonuclear ao seu redor, caracterizados como ruptura cística (Figura 1, B). Tais observações indicam uma possível relação entre a exposição a baixas dosagens de micotoxinas, especialmente FB1 e AFB1, e quadros de severa encefalite, corroborando com achados anteriores (Fernandes, 2005) onde verificou-se que drogas de ação estrogênica são capazes de gerar quadros severos de encefalite por $T$. gondii.

Embora as alterações mais importantes no tecido cerebral tenham sido decorrentes da infecção pelo parasita, uma vez que os animais somente intoxicados com micotoxinas apresentaram lesões menos significativas, a coexposição às micotoxinas e ao parasitismo tornou as lesões nesse tecido mais evidente. As lesões mais severas foram constatadas nos grupos I-FA e I-F, o que mesmo utilizando doses mais baixas, corroborou com os dados de Venturini et al. (1996), que observaram alterações mais severas em animais infectados e alimentados com micotoxinas (AFB1 ou T2) encontrando lesões semelhantes, tais como: proliferação de células da glia, infiltrados inflamatórios e alterações neuronais.

A observação de áreas de desmielinização em animais que receberam FB1, isolada ou associada a outras micotoxinas, pode ser explicada pela alteração no metabolismo de esfingolipídios no sistema nervoso central, já observada em fetos de ratos, levando a hipomielinização assim como dificuldades em atividades específicas do sistema nervoso central (Carratù et al., 2003). Tais relatos estão de acordo com Marasas et al. (1988), Bucci et al. (1996) que também associam a FB1 como responsável por danos cerebrais em animais de diversas espécies, assim como os relatos de Martorelli (2003), que observou apatia em animais alimentados com FB1 isolada ou associada a AFB1.

$\mathrm{Na}$ análise histopatológica do fígado foram observadas áreas de infiltrado inflamatório do tipo nodular, proliferação de ductos biliares, células apresentando degeneração vacuolar (Figura 1, C), necrose, células com citoplasma basofílico (Figura 1, D, d.1), gigantismo nuclear e hipertrofia celular (Figura1, D, d.2) e alguns grupos de células atípicas apresentando núcleos irregulares (Figura 1, D, d.3). As alterações observadas indicaram a influência do consumo de micotoxinas, uma vez que, tanto animais infectados quanto controles sem infecção apresentaram lesões semelhantes, de acordo com o tipo de micotoxina que ingeriram (I-FA, I-F, IMIX, C-FA, C-F, I-C e C-MIX), demonstrando os efeitos hepatotóxicos da fumonisina $\mathrm{B} 1$, da aflatoxina $\mathrm{B} 1$ e do próprio T. gondii. As observações estão de acordo com a literatura (Newberne e Butler, 1969; Wilson et al.,1985; Pozzi et al., 2000; Casado et al., 2001; Hinton et al., 2003) e sugerem que as lesões causadas pelas micotoxinas sejam dose dependentes, corroborando com as afirmações de Gelderblom et al. (2002) de que as respostas tóxicas e/ou carcinogênicas induzidas por AFB1 e FB1, no que se refere à indução e progressão das lesões hiperplásicas dependem do tempo de exposição e dosagem. Tal afirmação pode explicar o fato das lesões no presente estudo serem mais brandas do que as encontradas por outros autores. Os grupos C-CO e I-CO apresentaram lesões de forma mais discreta.

As alterações celulares, como gigantismo nuclear e hipertrofia celular, observadas nos animais tratados com FB1 e/ou AFB1 (C-F, C-FA, C-MIX, I-F, I-FA, I-MIX), sugerem uma relação intrínseca destas micotoxinas com alterações no metabolismo celular. Desta forma, o aumento nuclear poderia significar que as células encontravam-se no meio de um processo de multiplicação, observação que está de acordo com os relatos anteriores de Dilkin et al. (2003) e Hinton et al. (2003), sugerindo que as micotoxinas estimulem a proliferação de hepatócitos. Processos pré-neoplásicos, de um modo geral, apresentam também um aumento na multiplicação celular de forma desordenada. Dilkin et al. (2003) observaram um aumento no número de mitoses e hepatócitos distorcidos em suínos expostos a baixas dosagens de FB1 e AFB1, corroborando com os presentes achados.

A metade dos grupos que apresentaram gigantismo nuclear e hipertrofia celular também apresentou grupos de células atípicas (C-F, C-FA, I-F), exibindo núcleos disformes e arquitetura celular alterada. Tais células poderiam ser um início de um processo neoplásico ou pré-neoplásico, o que também foi previamente observado por outros autores; entretanto, os mesmos utilizaram doses de micotoxinas proporcionalmente maiores (Newberne e Butler, 1969; Purchase et al., 1975; Ueno et al., 1997; Dilkin et al., 2003).

Lesões hepáticas como infiltrados inflamatórios, focos de vacuolização e áreas de necrose foram observadas em grande parte de animais do grupo I-C. Isto leva-nos a crer que a infecção pela cepa ME49 T. gondii per si também é capaz de causar danos no fígado de camundongos (C57BL/ 6). Remington (1974) assim como Vischer et al. (1967) já referiam em seus trabalhos a possibilidade de danos hepáticos por cepas diferentes de $T$. gondii em outras espécies animais.

$\mathrm{Na}$ análise de tecido pulmonar, não foram encontradas alterações condizentes com quadros patológicos ocorridos antes da eutanásia dos animais. Os cortes de tecido renal apresentaram poucas alterações, que quando presentes, consistiam de discreta hipertrofia das células da parede dos túbulos nos grupos C-F, C-MIX, I-F, I-FA e I-MIX. Apenas no grupo I-CO foram observados quadros de glomérulo-nefrite com infiltrado inflamatório perivascular (Figura 1, E).

Pozzi et al. (2000), ao estudarem a FB1 e AFB1 em ratos Wistar, observaram alterações renais moderadas em todos 


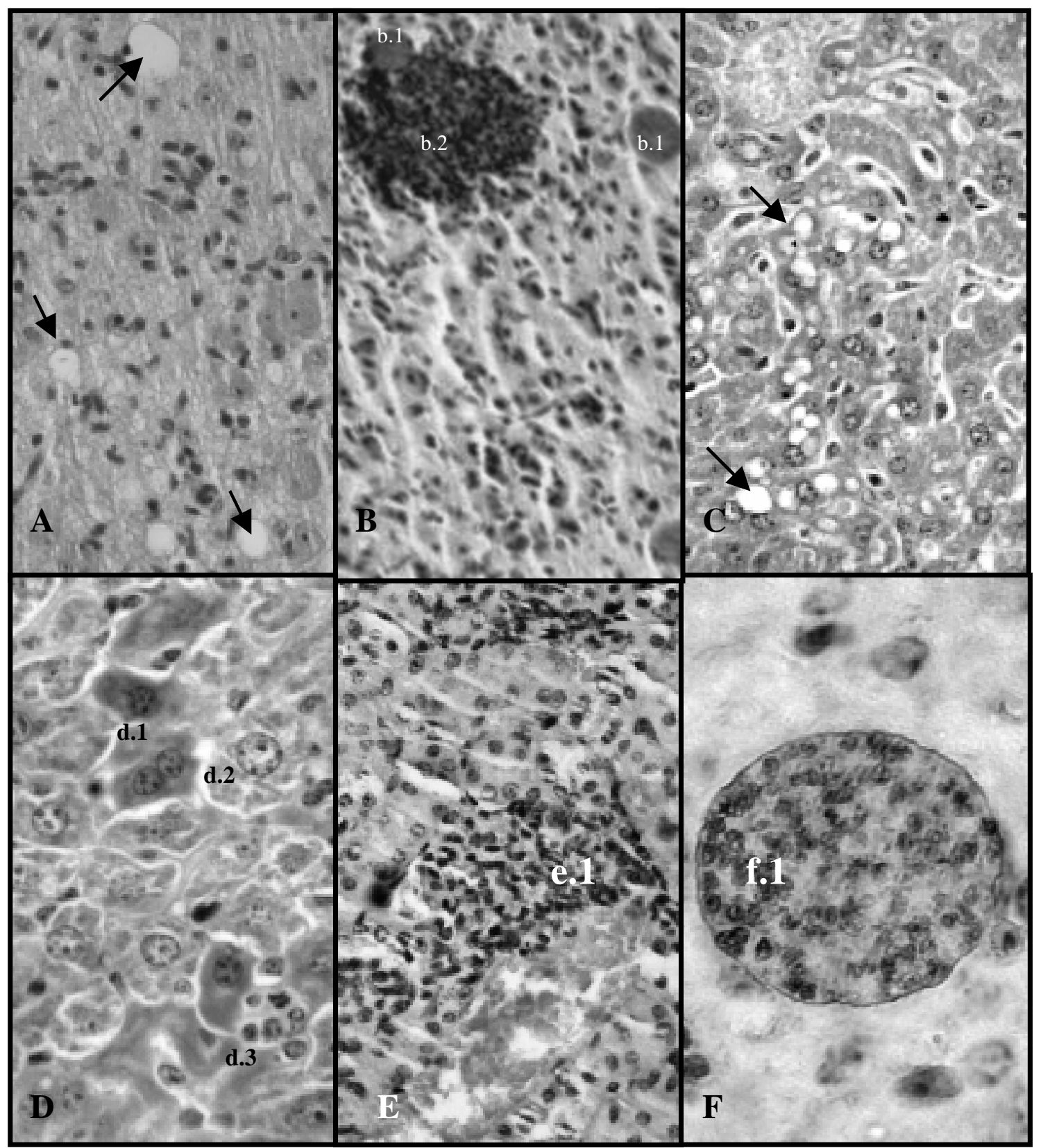

Prancha 1: Cortes de tecidos de camundongos C57BL/6 infectados por Toxoplasma gondii e alimentados com ração contendo micotoxinas. A - Setas apontando para áreas de desmielinização encefálica (HE, obj. 40x); B - Região do encéfalo apresentando cistos de T. gondii (b.1), um destes com intensa infiltração inflamatória adjacente (b.2; HE, obj. 20x); C - Setas apontando para vacuolização de hepatócitos (HE, obj. 40x); D - Corte hepático apresentando células com citoplasma basofílico (d.1), gigantismo nuclear e hipertrofia celular (d.2) e grupos de células atípicas (d.3; HE, obj. 60x); E - Corte renal apresentando infiltrado inflamatório periglomerular e perivascular (e.1; HE, obj. 40x); F - Região do encéfalo apresentando cisto de T. gondii marcado (f.1; imuno-histoquímica, obj. 100x).

os grupos tratados, apresentando degeneração vacuolar do epitélio tubular, desunião de células epiteliais e células com núcleo picnótico. Dimitri et al. (1998), ao administrarem aflatoxinas a coelhos (durante 4 meses), constataram alterações renais como congestão, degenerações nos túbulos (mais evidentes nos proximais) e hemorragias glomerulares. Em contrapartida, Casado et al. (2001), utilizando camundongos Swiss Webster, somente foram observados danos renais nos animais dos grupos tratados com FB1 e AFB1 por 90 dias (período mais longo do estudo). Nestes animais foram observadas congestão e hemólise.

No presente trabalho, apenas amostras do grupo I-CO apresentaram quadros de glomérulo-nefrite com infiltrado inflamatório perivascular. Tais achados não ocorreram nos grupos C-CO nem I-C, onde as variáveis "infecção" e "micotoxicose" ocorriam isoladamente, o que pode sugerir que a ação das micotoxinas (CTR e OA) associada à infecção 
por T. gondii seriam responsáveis por esses resultados. Os efeitos nefrotóxicos da ocratoxina $A$ já foram relatados na literatura em várias espécies animais (Creppy et al., 2004).

A análise de tecido muscular tanto esquelético quanto cardíaco não evidenciou alterações patológicas graves, sendo os achados mais relevantes os cistos de T. gondii encontrados em cortes de musculatura esquelética nos grupos I-F e I-FA.

Por meio da técnica de imuno-histoquímica foram marcados antígenos de estruturas parasitárias como cistos, formas livres íntegras ou em debris, tanto extracelulares quanto intracelulares. Apenas os animais infectados por T. gondii apresentaram resultados positivos nesta análise. Nos cortes de tecido cerebral puderam ser observados cistos bem marcados (Figura 1, F) e formas livres do parasita dispersas por diversas áreas do tecido. Formas livres de T. gondii e células positivamente reativas foram encontradas em cortes de fígado e musculaturas de animais alimentados com ração contendo ou não micotoxinas. Cistos foram encontrados nos tecidos musculares de animais dos grupos I-C, I-F e I-FA. Não foram encontrados traços de marcação positiva para presença de $T$. gondii no pulmão e rins dos animais estudados.

Os resultados obtidos na análise imuno-histoquímica, no presente trabalho, demonstrando formas livres do protozoário em animais controle infectados, corroboram com as afirmações sobre a possível reativação espontânea da cepa
ME49 de T. gondii em C57BL/6 ou uma perpetuação da infecção aguda como ainda é sugerido por diferentes pesquisadores (Suzuki, 2002). Tal evento, envolvendo casos de recrudescência de infecções crônicas e casos de parasitemia recorrente também já foi descrito por outros pesquisadores com cepas diferentes do parasita e de animais (Conley e Jenkins, 1981; Ferguson et al., 1989). Tais processos têm sido correlacionados com a manutenção da resposta imune em níveis efetivos pelo hospedeiro.

O rompimento cístico per si, num único foco, não é suficiente para caracterizar a reativação da infecção, uma vez que existem referências na literatura de animais que tiveram rompimentos espontâneos de cistos, sem a manifestação de alterações patológicas esperadas durante um quadro de reagudização. Desta maneira, Conley e Jenkins (1981), Ferguson et al.(1989) e Suzuki (2002) relacionam tal evento, de forma pontual, a fatos esporádicos que auxiliam na manutenção da resposta imune.

\section{Conclusões}

No presente estudo foi observado que a coexposição do hospedeiro ao parasitismo e às micotoxinas estudadas causou danos teciduais mais expressivos. Mesmo em baixas dosagens, as micotoxinas desencadearam quadros de alterações patológicas no encéfalo, rim e fígado, sendo o último o órgão mais acometido pelos efeitos deletérios das mesmas, no modelo animal avaliado.

\section{Agradecimentos}

Agradecemos à Dra Helene Santos Barbosa, Laboratório de Biologia Estrutural do Instituto Oswaldo Cruz, pela gentileza em ceder a cepa ME-49 de T. gondii e o anticorpo policlonal, e ao Instituto Oswaldo Cruz pelo fomento à pesquisa.

\section{Referências}

AMENDOEIRA, M.R.R. Mecanismos de transmissão da toxoplasmose. An.Acad.Nac.Med., v. 155, n. 4, p. 224-225, 1995.

AMENDOEIRA, M.R.R. et al. Toxoplasma gondii Nicolle e Manceaux, 1909 (Apicomplexa: Sarcocystidae) e a toxoplasmose. Rev.Souza Marques, v. 1, n. 1, p. 15-35, 1999.

$\mathrm{BUCCI}, \mathrm{T}$. et al. Leucoencephalomalacia and hemorrhage in the brain of rabbits gavaged with mycotoxin fumonisin B1. Nat. Toxins, v. 4, p. 51-52, 1996.

CARRATÙ, M.R. et al. Antinutritional effects of fumonisin B1 and pathophysiological consequences. Toxicology Letters, v. 140-141, p. 459-463, 2003.

CASADO, J.M. et al. Experimental subchronic mycotoxicosis in mice: individual and combined effects of dietary exposure to fumonisins and aflatoxin B1. Food Chem. Toxicol., v. 39, p. 579-586, 2001.

CONLEY, F.K. E JENKINS, A. Immunohistological study of the anatomic relationship of Toxoplasma antigens to the inflammatory response in the brains of mice chronically infected with Toxoplasma gondii. Infect.Immun., v. 31, n. 3, p. 1184-1192, 1981.

CREPPY, E.E. et al. Synergistic effects of fumonisin B1 and ochratoxin A: are in vitro cytotoxicity data predictive of in vivo acute toxicity? Toxicology, v. 201, p.115-123, 2004.

DILKIN, P. et al. Toxicological effects of chronic low doses of aflatoxin $\mathrm{B} 1$ and fumonisin B1-containing Fusarium moniliforme culture material in weaned piglets. Food and Chemical Toxicology, v. 41, p. 13451353, 2003.
DIMITRI, R.A. et al. Effect of aflatoxin ingestion in feed on body weight gain and tissue residues in rabbits. Mycoses, v. 41, p. 87-91, 1998.

DUBEY, J.P. Toxoplasmosis - a waterborne zoonosis. Vet.Parasitol., v. 126, p. 57-72, 2004.

DUBEY, J.P. E BEATTIE, C.P. Toxoplasmosis of animals and man. Boca Raton, FL: CRC Press, 1988.

FERGUSON, D.J.P. et al. Tissue rupture in mice chronically infected with Toxoplasma gondii. Parasitol.Res., v. 75, p. 599-603, 1989.

FERNANDES, B.C.T.M. et al. Toxoplasma gondii: dinâmica populacional e células mielóides durante o curso de infecções crônicas em camundongos C57BL/6. Ciência Rural, v. 35; n. 6, p. 1-7, 2005.

FERREIRA, M.S. E BORGES, A.S. Some aspects of protozoan infections in immunocompromised patients - a review. Mem.Inst.Oswaldo Cruz, v. 97, n. 4, p. 443-457, 2002.

FINK-GREMMELS J. Mycotoxins: Their implications for human and animal health. Vet.Q., v. 21, p. 115-120, 1999.

GELDERBLOM, W.C.A. et al. Interaction of fumonisin B1 and aflatoxin $\mathrm{B} 1$ in a short-term carcinogenesis model in rat liver. Toxicology, $\mathrm{v}$. 171, p. 161-173, 2002.

HINTON, D.M. et al. Immunotoxicity of aflatoxin B1 in rats: effects on lymphocytes and the inflammatory response in a chronic intermittent dosing study. Toxicological Sciences, v. 73, p. 362-377, 2003.

HUSSEIN, H.S. E BRASEL, J.M. Toxicity, metabolism, and impact of mycotoxins on humans and animals. Toxicology, v. 167, p. 101-134, 2001. 
MARASAS, W.F.O. et al. Leukoencephalomalacia in horse induced by fumonisin B1 isolated from Fusarium moniliforme. Onderstepoort J.Vet.Res., v. 55, p. 197-203, 1988.

MARTORELLI, R.A. Interação entre deficiências imunitárias por micotoxinas e parasitoses em mamíferos, utilizando o Toxoplasma gondii como modelo experimental. 2003. Tese (Doutorado)-Curso de Pós-graduação em Biologia Parasitária - Instituto Oswaldo Cruz, Fiocruz.

NICOLLE, C.E. MANCEAUX, L. Sur un protozoaire nouveau du gondii. C. R. Hebd. Séances Acad. Sci., v. 148, p. 369-372, 1909.

NEWBERNE, P.ME BUTLER, W.H. Acute and chronic effect of aflatoxin $\mathrm{B} 1$ on the liver of domestic and laboratory animals: a review. Cancer Res., v. 29, p. 236-250, 1969.

PERAICA, M. et al. Toxic effects of mycotoxins in humans. Bulletin of the WHO, v. 77, n. 9, p. 754-766, 1999.

PITT, J.I. Toxigenic fungi: which are important? Med.Mycol., v. 38, n. Suppl.1, p. 17-22, 2000.

POZZI, C.R. et al. Effects of prolonged oral administration of fumonisin B1 and aflatoxin B1 in rats. Mycopathologia, v. 151, p. 21-27, 2000.

PURCHASE, I.F.H. et al. Biological testing of food grown in the Transkei. Food Chemical Toxicology, v. 13, p. 639-647, 1975.

REMINGTON, J.S. Toxoplasmosis in the adult. Bull.NY Acad.Med.,v. 50, p. 211-227, 1974.
REMINGTON, J.S. et al. Toxoplasmosis. In: Remington JS, Klein JO, editors. Infectious diseases of fetus and newborn infant. Philadelphia, Pennsylvania:W.B. Sauders Company, 2001, p. 205-346.

SUZUKI, Y. Immunopathogenesis of cerebral Toxoplasmosis. J.Infec.Dis, v. 186, n. Suppl 2, p. S234-S240, 2002.

TENTER, A.M. et al. Toxoplasma gondii: from animals to humans. International Journal for Parasitology, v. 30, p. 1217-1258, 2000.

UENO, Y. et al. Fumonisins as a possible contributory risk factor for primary liver câncer: a 3-year study of corn harvested in Haimen, China, by HPLC and ELISA. Food and Chemical Toxicology, v. 35, p. 1143-1150, 1997.

VASANTHI, S. E BHAT, R.V. Mycotoxins in foods-occurrence, health e economic significance e food control measures. Ind. J. Med. Res., v. 108, p. 212-224, 1998.

VENTURINI, M.C. et al. Mycotoxin T-2 and aflatoxin B1 as immunosuppressors in mice chronically infected with Toxoplasma gondii. J. Comp. Path., v. 115, p. 229-237, 1996.

VISCHER, T.L. et al. Two cases of hepatitis due to Toxoplasma gondii. Lancet, v. 2, p. 919-921, 1967.

WILSON, T.M. et al. Hepatic neoplastic nodules, adenofibrosis, and cholangiocarcinomas in male Fisher rats fed corn naturally contaminated with Fusarium moniliforme. Carcinogenesis, v. 6, p. 1155-1160, 1985. 